\title{
Laboratory Accreditation in the United States
}

\section{Maureen A. Breitenberg}

U.S. DEPARTMENT OF COMMERCE National Institute of Standards and Technology

Standards Code and Information program Office of Standards Services Gaithersburg, MD 20899 
NATIONAL INSTITUTE OF STANDARDS \&

TECHNOLOGY

Research Information Centex

Geithersburg, MD 20899 


\section{Laboratory Accreditation in the United States}

\section{Maureen A. Breitenberg}

U.S. DEPARTMENT OF COMMERCE

National Institute of Standards and Technology Standards Code and Information program Office of Standards Services

Gaithersburg, MD 20899

May 1991

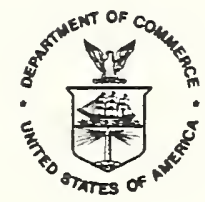



Foreword

The Standards Code and Information Program periodically develops and publishes standards-related documents as a service to producers and users of standards, both in government and in the private sector. This report is a sequel to NBSIR 87-3576, The ABC's of Standards-Related Activities in the United States, and NBSIR 88-3821, The ABC's of Certification Activities in the United states, and is designed to provide the reader with additional information on one standardsrelated activity - laboratory accreditation. This document is an introduction to laboratory accreditation for those not fully familiar with the subject. We intend that this material be informative and serve to stimulate wider interest in this field. Readers interested in this area may wish to review NIST SP 808, Directory of Federal Government Laboratory Accreditation/Designation Programs, which provides updated information on federal government laboratory accreditation and similar type programs conducted by the federal government. Companion volumes on state and local government and private sector laboratory accreditation programs are currently in preparation. 


\section{Acknowledgements}

I would like to thank Mr. Charles Hyer, who has done extensive work in this area and has compiled directories of state/local government and private sector laboratory accreditation programs. I would also like to thank John Donaldson and Pat Cooke of the NIST Standards Code and Information Program; Walter Leight of the NIST Office of Standards Services, Henry Oppermann of the NIST Weights and Measures Program; Nancy Trahey of the NIST National Voluntary Laboratory Accreditation Program; Anne Marie Hollister of the law firm of Miles and Stockbridge; and many others for their careful review of and comments on this document. 


\section{Abstract}

This paper, the third in a series that includes NBSIR 87-3576, The ABC's of Standards-Related Activities in the United States, and NBSIR 88-3821, The ABC's of Certification Activities in the United States, is designed to provide information on laboratory accreditation to readers not entirely familiar with this topic. This report highlights some important aspects on the topic, furnishes information necessary to make informed decisions on the selection and use of laboratories, and serves as background for using other available documents and services. Readers interested in this area may also wish to review NIST SP 808, Directory of Federal Government Laboratory Accreditation/Designation Programs, which provides updated information on federal government laboratory accreditation and similar type programs conducted by the federal government. Companion volumes on state and local government and private sector laboratory accreditation programs are currently in preparation.

Key Words: accreditation; calibration; conformance testing; laboratory accreditation; NVLAP; quality assurance; testing 

$\underline{\text { Page }}$

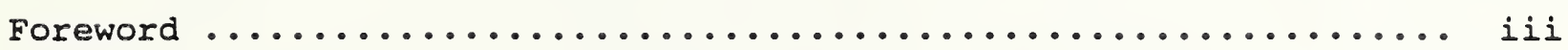

Acknowledgements $\ldots \ldots \ldots \ldots \ldots \ldots \ldots \ldots \ldots \ldots \ldots \ldots \ldots \ldots \ldots \ldots \ldots$ iv

Abstract $\ldots \ldots \ldots \ldots \ldots \ldots \ldots \ldots \ldots \ldots \ldots \ldots \ldots \ldots \ldots \ldots \ldots \ldots \ldots \ldots$

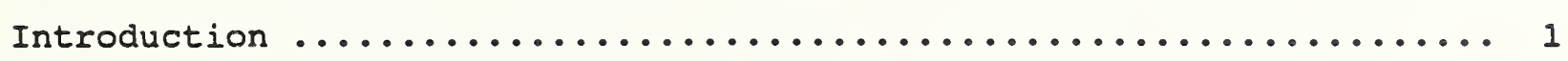

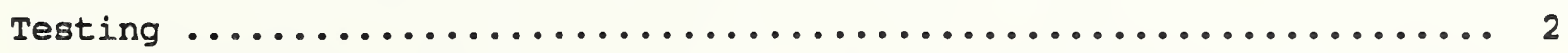

Benefits to a Laboratory that Participates in an

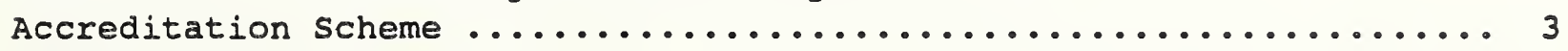

Eligibility Requirements for Accreditation ................. 3

Terminology $\ldots \ldots \ldots \ldots \ldots \ldots \ldots \ldots \ldots \ldots \ldots \ldots \ldots \ldots \ldots \ldots \ldots \ldots$

scope of Accreditation $\ldots \ldots \ldots \ldots \ldots \ldots \ldots \ldots \ldots \ldots \ldots \ldots \ldots \ldots \ldots \ldots$

Criteria for Evaluating/Accrediting Laboratories ............. 5

U.S. Accreditation Programs ..........................

International/Regional Cooperation in Testing/Laboratory

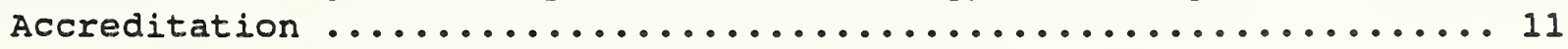

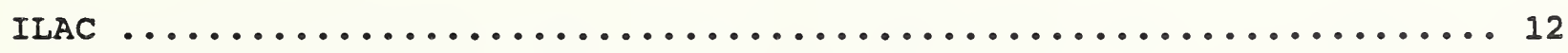

Importance of Laboratory Accreditation to Trade ............... 13

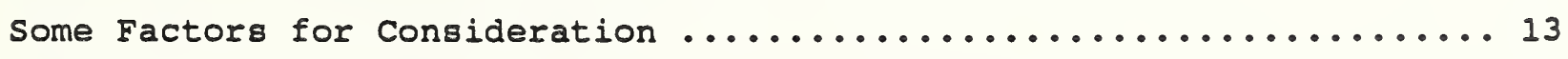

summary $\ldots \ldots \ldots \ldots \ldots \ldots \ldots \ldots \ldots \ldots \ldots \ldots \ldots \ldots \ldots \ldots \ldots \ldots \ldots \ldots \ldots$

References $\ldots \ldots \ldots \ldots \ldots \ldots \ldots \ldots \ldots \ldots \ldots \ldots \ldots \ldots \ldots \ldots \ldots \ldots \ldots \ldots \ldots$

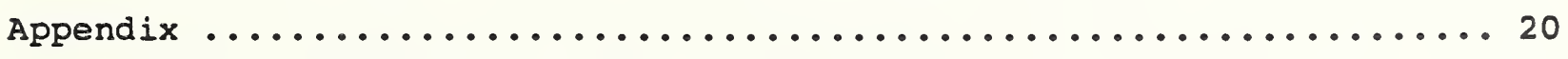





\section{INTRODUCTION}

Testing laboratories support billion-dollar industries and affect the operation of our entire regulatory system. Major corporate and regulatory decisions are made daily on the basis of data produced by such testing laboratories. Test data are used in many tasks, including: product design and research; quality control prior to acceptance of incoming materials and components, during production, and prior to shipment/sale; in insurance underwriting; meeting contractual agreements; satisfying government regulatory requirements; certification and labeling; buyer protection and information; product comparisons; building and structure design, construction and related engineering tasks; medical and health services; environmental protection; product operation, maintenance and repair; legal proceedings; and forensic work. Flawed test data can result in the sale or operation of defective products or services which are capable of causing serious injury to the user or harm to the environment. Defective products, such as fire detection and mitigation equipment, security alarms, aircraft, and autos may also be responsible for serious injury or death to unsuspecting bystanders.

One method to ensure the quality and accuracy of test data is through the accreditation of laboratories. Laboratory accreditation provides some assurance of the technical proficiency and competence of a laboratory to assess a product's or service's conformance to a set of prescribed standards. Laboratory accreditation is defined in the International organization for standardization (ISO) and the International Electrotechnical commission (IEC) Guide $2{ }^{1}$ as: "formal recognition that a testing laboratory is competent to carry out specific tests or specific types of tests." A footnote to this Iso/IEC definition indicates that laboratory accreditation "may cover the recognition of both the technical competence and impartiality of a testing laboratory or only its technical competence." The inclusion or exclusion of a requirement for impartiality is only one of many differences between the approval criteria used in various U.S. laboratory accreditation schemes. Differences in requirements or criteria for accreditation must be considered in evaluating a particular scheme.

It should be noted that the lack of accreditation does not necessarily imply that the laboratory is not technically competent, for not all laboratories seek or require accreditation. Moreover, accreditation programs may not exist in a laboratory's field of operation.

Since most U.S. laboratory accreditation/designation schemes have been designed to meet particular governmental or private sector needs, such schemes tend to take distinctive forms and use different sets of procedures to assure that a laboratory has sufficient competence to perform the specified testing. Some schemes entail only a simple review of data submitted by a laboratory with no attempt at verification. Others require a full scale on-site evaluation of the laboratory's facilities, staff and equipment, and include audits, quality system

1 The International organization for standardization (ISO) is a worldwide federation of 89 national standards bodies. Iso covers standardization in all fields, except the electrical and electronics fields which are covered by the International Electrotechnical Commission (IEC). IEC has members from over 40 countries which represent some 808 of the world's population. Together ISO and IEC form the world's largest nongovernmental system for voluntary industrial and technical collaboration in the field of standardization. 
review, and proficiency testing. Comparable programs, even those which are conducted by the same organization or government agency, may include different types or number of assessment procedures and may provide differing degrees of assurance regarding a laboratory's competency.

While a close interrelationship exists among accreditation, standardization, quality system registration, and certification, these areas are distinct. Certification is the process of providing assurance that a product or service conforms to a standard or specification. Some (but not all) certification programs mandate that accredited laboratories conduct any required testing. However, there are laboratory accreditation schemes which are not associated with a certification program. Certification and laboratory accreditation programs both rely on standards, but not all standards are intended for these uses. An evaluation of a manufacturer's or laboratory's quality system may be part of the certification and laboratory accreditation process; however, quality system evaluations and registrations may also be conducted independently.

Because accreditation, standardization, quality system registration, and certification are linked, strengths as well as deficiencies in any one area can have significant consequences for the others. For example, improvements in test method standards can significantly increase the capability of a laboratory to produce valid test data.

This paper is intended to be an introduction to some of the important aspects of laboratory accreditation. Interested readers are encouraged to increase their knowledge of the field by taking advantage of other available publications and services described in the paper, footnotes and appendix.

\section{TESTING}

Testing laboratories differ widely in size, legal status, purpose, range of testing services offered, and technical competence. They may be government regulatory laboratories, government research laboratories, or government supported laboratories -- at the federal, state or local levels. They may also be college/university laboratories, independent private sector laboratories, laboratories affiliated with or owned by industrial firms, or manufacturers' inhouse laboratories. Test laboratories may be for-profit or nonprofit. They may operate facilities in one or more locations and even in one or more countries. They may offer a limited range of testing services or services in many fields. There are almost as many different types of laboratories providing testing services as there are different types of users of the test data produced.

A test is defined by ISO/IEC Guide 2 as a: "technical operation that consists of the determination of one or more characteristics of a given product, process or service according to a specified procedure." Test data result from the performance of a test. If the test method procedure or standard is well written, it is sufficient that the test data comply with the standard's accuracy and variability requirements.

Accuracy (or bias) refers to the degree of departure of a test result from the "true value." For example, if a product is weighed and the result is $5.1 \mathrm{~kg}$ (when the true value is $5.0 \mathrm{~kg}$ ), the test or measurement is inaccurate by $.1 \mathrm{~kg}$. The degree of accuracy needed will depend on the characteristic being tested and the impact of errors on the ability of the product, process, or service being tested to perform in an acceptable manner. 
Variability (or precision) refers to the degree of difference between the results from several repetitions of the same test. For example, suppose a product weighs $5.0 \mathrm{~kg}$. If that product is weighed three times and the recorded weights are 5.1 $\mathrm{kg}, 4.9 \mathrm{~kg}$, and $5.0 \mathrm{~kg}$, then these results vary less (from the actual weight of $5.0 \mathrm{~kg}$ ) than recorded weights of $4.5 \mathrm{~kg}, 5.4 \mathrm{~kg}$ and $5.5 \mathrm{~kg}$.

Variability can also be defined in terms of repeatability, a measure of the variation among results when the same or similar test is repeated within ONE laboratory, and reproducibility (or replicability), a measure of variation of results from similar tests conducted in DIFFERENT laboratories.

Problems with accuracy and variability of test results occur not only because of errors made by the laboratory staff performing the test or defects in the test equipment used, but result from other factors as well, such as flaws or variables in the test method or in the sample selection process.

\section{BENEFITS TO A LABORATORY THAT PARTICIPATES IN AN ACCREDITATION SCHEME}

The desire to satisfy regulatory requirements is a primary reason for a laboratory to participate in an accreditation program. Congress, state and local governments may mandate by law that specific types of testing be done by an accredited laboratory. Federal, state and local government agencies may also impose such a requirement through regulations issued under their own legal authority. Laboratories may also have to be accredited to meet testing requirements imposed by a foreign government on various products imported into that country.

Many laboratories also participate in an accreditation program as an outside check of their internal quality control procedures; as proof of competence to higher level management within the organization; as a competitive advantage over unaccredited laboratories; as a means of protection in liability proceedings; or to establish credibility with the public. Contracts or procurement requirements sometimes dictate the use of an accredited laboratory to conduct required testing. A laboratory desiring to compete for such work would seek accreditation. Laboratories sometimes obtain reduced rates for medical care and other insurance by providing proof through accreditation of a safe working environment. Accreditation might also be imposed as a condition of sale by a laboratory's purchaser.

The reasons for and benefits of seeking accreditation are as diverse as the laboratories themselves. In general, however, laboratories participate in accreditation programs in expectation of an economic return on the resources they invest to obtain accreditation.

\section{ELIGIBILITY REQUIREMENTS FOR ACCREDITATION}

Eligibility requirements for accreditation vary among programs. Some federal programs restrict eligibility to state government laboratories, such as NIST's program for accrediting state weights and measures laboratories. Other programs impose different restrictions on eligibility. For example, the U.S. Department of Agriculture (USDA) program for inspecting grain for export limits the number of approved laboratories in a given geographical area to ensure that each approved laboratory will have an adequate market share. 
Some accreditation programs are restricted to laboratories operated by the accrediting body, such as the Department of Veterans Affairs' (VA) program for to accrediting its medical center laboratories. This type of program falls into a categorical gray area between laboratory accreditation and internal quality assurance -- since elements of both are present. Other programs restrict eligibility to members of the accrediting organization. It is generally desirable that a program impose as few restrictions on eligibility as possible.

\section{TERMINOLOGY}

The terminology used to refer to a laboratory which satisfies the criteria established by different types of laboratory evaluation programs varies greatly. Typical terms include "accredited," "designated," "inspected, " "accepted," or even "nationally recognized." Even the same term, such as "accredited," may be used by different programs to signify very different types of assessment and assessment procedures. Different terms may also have different legal implications, or may reflect differences between various agencies' or organizations' legal authority to conduct specific programs.

The term laboratory "designation" is increasingly being used instead of "accreditation" for schemes in which government agencies, public authorities, certification bodies, and others identify or "designate" one or more laboratories to perform specific types of testing for their own use or for the purpose of implementing regulations, standards, or specifications in which the organization or agency has an interest. Regulators, certifiers and others sometimes designate test laboratories through a contractual or similar relationship with the laboratory. The use of the term "designation" may be preferable, particularly if the degree of assessment of technical competence is less than that usually encompassed under accreditation. (See Reference 1.)

There is also a distinction between the acceptance body (the organization responsible for accepting and using the data produced by an accredited laboratory) and the accrediting body (the body that administers the laboratory accreditation program and issues the accreditation). For example, NIST's National Voluntary Laboratory Accreditation Program (NVLAP) may be the accreditation body for a laboratory which tests radiation dosimeters, but the acceptance body -- the body which uses the data to regulate dosimeters -- would be the Nuclear Regulatory Commission (NRC). The reader should be aware of this important difference when reviewing information on laboratory accreditation programs.

\section{SCOPE OF ACCREDITATION}

Laboratories can be accredited in a number of ways. One way is to accredit a laboratory to test in an entire field of testing. The American society for Testing and Materials (ASTM) Standard E 1224-88: "Standard Guide for Categorizing Fields of Testing for Laboratory Accreditation" defines a field of testing as a "broad sphere of science, engineering, or technology used to describe a general area of testing for classification purposes." ASTM E 1224 lists these fields as acoustic and vibration testing, biological testing, chemical testing, construction materials testing, electrical testing, geotechnical testing, mechanical testing, medical testing, metrology, non-destructive testing, optics and photometry, and thermal testing. A laboratory can also be accredited in a 
scientific discipline, such as biochemistry, or for a specific technology (such as gene splicing), or in relation to specific products, such as blood product testing or concrete sample testing. Accreditation can also be limited to the conduct of specified test methods.

In general, the broader the scope of approval, the more difficult and time consuming it is for the accrediting body to thoroughly assess the laboratory's ability to perform all test methods within that scope. However, the narrower the scope of accreditation, the more likely it is that a laboratory that performs a broad range of testing will have to obtain multiple accreditations.

\section{CRITERIA FOR EVALUATING/ACCREDITING LABORATORIES}

Standards organizations have recognized the importance of laboratory competence and accreditation. The Organization for Economic Cooperation and Development (OECD) has published a "Code of Good Laboratory Practice." ISO and IEC have published Guide 25, "General Requirements for the Competence of Calibration and Testing Laboratories," which establishes general requirements for laboratory competency to conduct specific calibrations or tests. In the area of laboratory accreditation, ISO and IEC have published Guide 38: General Requirements for the Acceptance of Testing Laboratories; Guide 54: Testing Laboratory Accreditation Systems - General Recommendations for the Acceptance of Accreditation Bodies; and Guide 55: Testing Laboratory Accreditation Systems - General Recommendations for operation.

In the United States, a number of organizations have attempted to address the issue of judging technical competence through standards documents, such as the American Society for Testing and Materials (ASTM) E 994, "Standards Guide for Laboratory Accreditation Systems," and ASTM E 548, "Practice for Generic Criteria for Use in Evaluation of Testing Laboratories and Inspection Agencies." Federal agencies have published guides and related manuals in this area, such as the Food and Drug Administration's (FDA) Good Laboratory Practice (GLP) guidelines.

The following list contains general criteria which may be used in evaluating laboratories. Any or all of these criteria may be used during the assessment process. In addition, criteria specific to the type of laboratory being accredited, the nature of the work being performed, and the purpose for which the accreditation program was established may also be imposed.

2 The European Committee for Standardization (CEN) has published a series of standards or European Norms (EN) (referred to as the EN 45000 series based on the ISO Guides listed above. The series includes EN 45001 Generi l Criteria for the operation of Testing Laboratories (1989), EN $45002-$ General Criteria for the Assessment of Testing Laboratories (1989), EN 45003

- General Criteria for Laboratory Accreditation Bodies (1989), and prEN 45019

- Guidance on Specific Aspects of Testing and Certification of Personnel (1989). 


\section{Laboratory Organization/Independence (No Conflict-of-Interest)}

The laboratory should be a legal entity organized in a manner which permits the performance of all required functions in a satisfactory fashion. In addition, there may be a requirement that the laboratory be impartial or independent, that is, free from any outside influence -- monetary, organizational, or otherwise -which might bias the integrity of the work performed.

\section{Financial Stability}

The laboratory may be required to have sufficient resources to enable it to properly use and maintain the test equipment and facility, to satisfactorily perform all required functions, and to adequately indemnify itself against financial liabilities/penalties resulting from its operations.

\section{On-site Inspection}

The laboratory may be required to pass an on-site evaluation by assessors appointed by the accrediting body. The evaluation should include a review of all relevant information concerning the ability of the applicant to comply with the accreditation criteria.

\section{Staff Oualifications Requirements}

The laboratory may be required to demonstrate that its personnel are qualified or licensed (where necessary). Each staff member should have the education, training, knowledge, and experience necessary to perform the tasks assigned and an appropriate level of supervision should be maintained. The training of each staff member should be kept current and should be documented.

\section{Adequate Quality System}

An operational quality system appropriate to the type and amount of work performed by the laboratory may be required. The system should be reviewed by management on a periodic basis and revised as needed to ensure continued acceptable performance. A quality system should be suitably documented in a comprehensive, up-to-date quality manual that is readily available for consultation by staff.

\section{Sampling Requirements}

If test materials are received by the laboratory in quantities larger than the amount required for the test, the laboratory may be required to sample the material in such a manner as to ensure that the sample tested is representative of the entire quantity of material received. Where sample selection is the responsibility of the test laboratory, appropriate sampling methods and/or techniques should be used.

\section{Sample Control/Integrity Requirements}

The laboratory may be required to have an effective system to ensure both the identity and integrity of test samples. Maintaining the integrity of the sample involves preventing it from being damaged during all stages of collection, shipping, storage, or handling. Such damage can include: physical damage; loss of part of the sample due to leakage; contamination by foreign materials; failure to maintain the sample within appropriate temperature or atmospheric conditions; 
or other deterioration, such as that which can occur if samples are held too long before testing. If the sample may be used as legal evidence, a complete record may be required on who had custody of the sample from collection through testing and (when needed) until its disposal.

\section{Statistical Methods Requirements}

The statistical methods used to interpret or to provide additional information about test data should be appropriate and adequate for the type and level of testing undertaken. Control charts, which help distinguish random errors from systematic (assignable cause) errors or variations, should be employed as needed to alert laboratory personnel to potential problems in test procedures or equipment.

\section{Recordkeeping Requirements}

A laboratory may be required to maintain all test records, observations, calculations and derived data for all tests it performs for a given number of years. ISO/IEC Guide 38 recommends a guideline period of at least 6 years or as otherwise required by $l$ aw or by the accrediting body.

\section{Test Report Content/Format Requirements}

Test reports should include all information relevant to sample selection, test performance, and test results. Such information should be displayed in a format that is easy to read and understand. Data included in such reports should be routinely audited and validated, that is checked for questionable values and accepted or rejected based on an established set of criteria. Audit levels (the amount of work subject to review and the extent of those reviews) should be appropriate for the type and amount of work being performed as well as the skill of the analyst or technician conducting the tests.

\section{Available Operational Manuals/Instructions}

The laboratory may be required to have readily available instructions on the operation and maintenance of all materials and equipment; copies of the test methods and standards employed, along with any additional instructions needed for their application; sample selection and handling procedures; and other relevant information needed to ensure the quality of the work performed.

\section{Periodic Re-audit of Facilities}

An accredited laboratory may be subject to periodic reassessment to ensure its continued compliance with all accreditation requirements. Any significant changes in the laboratory's operations should be reported as soon as possible to the accrediting body, which should then promptly decide whether the accreditation should be continued or terminated.

\section{Participation in Proficiency Testing Program}

Proficiency testing evaluates the competency of a laboratory by comparing results from that laboratory with results obtained from other laboratories from tests performed on the same or similar items. Applicants may be required to satisfactorily complete specified proficiency tests, particularly in the application of test methods critical to the evaluation of the product or service. 


\section{Adequacy of Facilities and Equipment}

The laboratory should own or have access to all equipment required to correctly perform all test methods for which accreditation is sought. In addition, the facility should permit test methods to be conducted in a controlled environment to prevent any adverse effects on the accuracy of the test result. Specifically, the testing environment should be free from excessive temperatures, temperature fluctuations, dust, moisture, dryness, vibration, and electromagnetic or other interference. The laboratory should also have adequate lighting, heating and ventilation. When needed, specialized facilities, such as clean rooms, should be available.

\section{Equipment Maintenance/Repair/Calibration Requirements}

Equipment calibration, preventive maintenance and repair procedures and the choice of reference materials ${ }^{3}$ used for calibration should be appropriate for the nature and amount of the work being performed. Equipment calibrations should be traceable to some ultimate or national reference standard. 5 Complete records should be maintained on all calibration, maintenance and repair procedures performed.

\section{Adequate Control over Subcontractors}

The laboratory may be required to have a system to ensure that testing and related work performed by another party under contract is of acceptable quality. The nature of the system should be appropriate for the type and amount of work performed by the subcontractor. The laboratory should also be able to provide to the accrediting body or other interested parties adequate evidence of the competency of all subcontractors.

\section{Appeals Procedure}

The laboratory may be required to have a mechanism to deal with technical questions, appeals, complaints and challenges, originating either from the customer or from interested regulatory or accrediting bodies.

3 Reference materials are defined by ISO Guide 30 as a "material or substance one or more properties of which are sufficiently well established to be used for the calibration of an apparatus, the assessment of a measurement method, or for assigning values to materials."

4 "Traceability means the ability to relate individual measurement results to national standards or nationally accepted measurement systems through an unbroken chain of comparisons." Examples of traceability include: equipment calibrated by NIST; equipment calibrated using NIST transfer standards (materials previously measured by NIST); or equipment calibrated using other NIST calibrated equipment. For further information on traceability, see Reference 7.

5 Reference standards include those involving dimension (i.e., length, diameter, angle, or volume and density), mechanical properties (i.e., flow rate or airspeed), ionizing radiation measurements, time and frequency, etc. 
Note: Accreditation programs do not necessarily include all of the above technical criteria in their evaluation process. The choice of criteria depends on the degree and type of assurance sought by the accrediting body regarding a laboratcry's stability and competence, the cost associated with the adoption of each criterion, and the complexity of the test method(s) included in the accreditation. There may also be differences between programs using the same technical criteria but varying the frequency and intensity of their application. For example, proficiency testing may be required annually or monthly, for all test methods or only the most important ones. Depending on these factors, an onsite inspection may be a one day inspection conducted by one assessor, or a week long inspection conducted by a team.

\section{U.S. ACCREDITATION PROGRAMS}

The U.S. laboratory accreditation system is different from that of most foreign countries. Most foreign accreditation bodies are public organizations or have some direct government involvement. There is also a growing tendency in foreign countries to run laboratory accreditation schemes in a coordinated fashion. In the United States, on the other hand, laboratory accreditation schemes are operated by all levels of government and by the private sector as well. There is no centralized coordinating body, though some coordination does take place between specific programs on their own initiative or through the intervention of other interested bodies, such as trade associations or professional societies. The different types of U.S. programs are briefly described below.

\section{Federal Government Laboratory Accreditation Programs in the United States}

Requirements for laboratory accreditation/designation programs within the federal government vary greatly. Some programs, such the National Voluntary Laboratory Accreditation Program (NVLAP), are quite comprehensive; others consist of only a minimal review of a laboratory's qualifications. The requirements and scope of each program have generally been tailored to meet specific agency needs; and (except for NVLAP) laboratory accreditation/ designation is not the primary program goal. In some cases, the accredited or designated laboratories provide only an initial product screening service, with federal laboratories maintaining final responsibility for producing the test data used in enforcing regulations, such as the Mine Safety and Health Administration's (MSHA) programs for conformity assessment of mining products and equipment.

Eligibility requirements for accreditation also vary among federal programs. Some restrict applications to state laboratories, such as NIST's program for accrediting state weights and measures laboratories. As noted earlier, one USDA program places limits the number of laboratories approved in a geographical area, and the VA program accredits only the laboratories of its medical centers. Some agencies, such as DOD's Defense Logistics Agency (DLA), designate or accredit laboratories found to be capable of performing specific tests on products procured by that agency. These programs are open only to potential government suppliers.

Terminology also varies by program. A 1989 GAO report noted the use of 10 different terms for accreditation with at least 18 different meanings by the 20 programs it reviewed. A given term, such as "accredited," can be used in the context of different program to signify different types of assessments and assessment procedures. Different terms may also have different legal 
implications or may reflect differences between various agencies' legal authority to conduct specific programs.

\section{State/Local Government Laboratory Accreditation Programs in the United States}

States administer many laboratory accreditation programs for a variety of reasons. In most cases, state and local government agencies accredit laboratories to test products regulated indirectly by requiring that such products be inspected and/or tested by an approved body. An example of the latter is the regulation of building and electrical products at the state or local government level by requiring that the products be tested/inspected and bear the mark of a recognized or approved testing laboratory. In other cases, the state or local government programs, like some federal programs, accredit or designate laboratories that provide a surveillance/screening service for testing product compliance. State/local government laboratories then usually maintain responsibility for producing the test data used in enforcement situations.

States also evaluate laboratories for other purposes, such as to assist them in enforcing federal regulations. For example, states have primary enforcement responsibility for the national requirements for ensuring the quality of public water systems. In carrying out this obligation, states accredit local laboratories to test drinking water. State and local authorities also accredit or designate laboratories to test products prior to their procurement by a state agency.

As with federal programs, state and local requirements for laboratory accreditation/designation vary greatly. Some programs are quite comprehensive, while others only include a minimal review of laboratory capabilities. The terminology used for accreditation also varies extensively.

\section{Private Sector Laboratory Accreditation Programs in the United States}

Private sector accrediting bodies administer laboratory accreditation programs for a variety of reasons, ranging from assisting laboratories in defending their competence in professional malpractice matters to assisting an industry to avoid government regulation by undertaking self-policing efforts. Many private sector programs are operated as an integral part of a private sector certification program. Programs can also be established to assist government agencies in enforcing regulations, such as in the testing of building and construction products. The criteria and terminology used in private sector laboratory accreditation/designation schemes again vary greatly.

Private sector programs also differ in size and scope. The American Association of Blood Banks (AABB) operates an accreditation program for blood bank and transfusion services which is recognized by many state authorities. The College of American Pathologists (CAP) program accredits hospitals and independent medical laboratories, and their program is used by the VA to ensure the competence of VA medical facilities. The American Association for Laboratory Accreditation (A2LA) operates an accreditation program for laboratories in a number of testing fields.

5 Information on each agency's legal authority is contained in NIST SP 808 - Directory of Federal Government Laboratory Accreditation/Desianation Programs. 
At the international level, the IEC Quality Assessment system for Electronic Components (IECQ) accredits testing facilities capable of demonstrating the compliance of electronic components to prevailing requirements and standards, which are based on IEC standards. This is part of a reciprocal worldwide certification system, in which certificates of conformity issued by an approved laboratory in one participating country are accepted by all other participating countries.

The IEC also operates the IEC System for Conformity Testing to Standards for Safety of Electrical Equipment (IECEE). The IECEE's objective is the reciprocal recognition of test results (not certification marks or certificates of conformity) among the participating countries. Equipment is tested by approved laboratories against prevailing specifications and requirements, including safety, based on IEC standards. Any electrical products for which there are appropriate IEC standards can be included within the program. If the product is found to conform to relevant IEC standards, the test certificate, accompanied by the test report, can then be presented to National Certification Bodies (NCB's) in other countries where certification is desired.

\section{INTERNATIONAL/REGIONAL COOPERATION IN TESTING/LABORATORY ACCREDITATION}

A number of mechanisms are used to facilitate the acceptance of test data produced by laboratories in more than one country. In some cases, a laboratory in one country will buy or establish a subsidiary within the physical boundaries of another country. Test data can then be exchanged and accepted between the parent laboratory and its subsidiary. In other cases, two or more organizations located in different countries agree to accept each other's test data.

Mutual acceptance of test data may also stem from bilateral or multilateral agreements established between governmental authorities requiring each party to accept test results from laboratories accredited by the otiner party (or parties). Mutual confidence in the competence of the other party's testing laboratories is vital to the success of such agreements.

One example is the multilateral Agreement on the International Carriage of Perishable Foodstuffs and on the Special Equipment to be Used for Such Carriage (ATP). The ATP is an international agreement which sets standards for the testing and uses of equipment which carry perishable foodstuffs. USDA certifies U.S. test stations and laboratories in accordance with requirements of the ATP. These bodies may then issue U.S. ATP certificates, which are recognized by other ATP signatories including: Austria, Belgium, Czechoslovakia, Denmark, Finland, France, Germany, Hungary, Ireland, Italy, Luxembourg, Morocco, Netherlands, Norway, Poland, Portugal, Spain, Sweden, the United Kingdom, and Yugoslavia.

NIST's National Voluntary Laboratory Accreditation Program (NVLAP) has established bilateral agreements between the United States and the National Association of Testing Authorities (NATA) in Australia, the Testing Laboratory Registration Council (TELARC) in New zealand, and the standards Council of Canada (SCC). Under these agreements, test results from laboratories accredited by each party are recognized by the other party to the agreement.

The European Community (EC) has established a regional mutual recognition scheme for regulated products. Under the so-called "new approach to technical harmonization of standards," each EC country is to provide to the EC a list of laboratories and other bodies (referred to as "notified bodies") which are 
authorized to declare that a regulated product conforms to the "essential requirements" spelled out in the applicable directive. Acceptable methods for conformity assessment are also listed in each directive. The test results of any notified body and subsequent product approval marking must be accepted by all other EC countries unless there is cause to believe that the product was improperly tested. Each EC country is responsible for ensuring that the bodies it notifies comply with the criteria for competence spelled out in the EN 45000 series.

In some mutual recognition schemes, the test results or reports, rather than certification marks, are mutually accepted. Provision may be made for a test report prepared in one participating country to be accepted in other participating countries for the purpose of obtaining certification or government marketing approval by the importing country. Examples are the programs coordinated by the European Free Trade Association (EFTA) for pressure vessels, ships' equipment, agricultural equipment and tractors, liquid fuel heating equipment, lifting apparatus (such as hoists, elevators, etc.) and gas appliances.

The required test report may have to establish conformity with applicable standard(8) which have been harmonized (made technically identical or equivalent in practice) between the importing and exporting countries, or the report may have to show compliance with technical requirements specified by the importing country alone. In the latter case, the requirements of the importing country may differ significantly from the requirements of the exporting country.

In some more advanced forms of mutual recognition arrangements, there is a mutual recognition of each other's marks or certificates of conformity, or the granting of a license to each party to label a conforming product with the other's certification mark, or with a mark common to all parties to the agreement. A laboratory accreditation scheme is usually an integral part of such an arrangement. An example of this type of scheme at the regional level is the European Committee for Electrotechnical Standardization (CENELEC) HAR Agreement to use a common marking scheme for electrical cables and cords complying with harmonized specifications. Cables and cords that have been tested by an accredited/designated body in one country and which bear the common HAR mark or a colored thread marking must be accepted without further testing or certification by the approval organizations of participating countries.

\section{ILAC}

One of the major events in international cooperation in the field of laboratory accreditation occurred in 1977 when Denmark and the United States convened an international conference in Copenhagen on the mutual recognition of test results. Ultimately this became the International Conference on Laboratory Accreditation (ILAC), whose purpose is to promote the development of national programs for accrediting test laboratories using harmonized accreditation criteria. Over forty countries have participated in ILAC, which has been the motivating force for the publication of eight ISO/IEC Guides on the subject of testing and laboratory accreditation. 
Laboratory accreditation has taken on increased significance as international recognition and acceptance of test data across national boundaries have assumed greater importance in the reduction of technical barriers to trade. As traded products become more complex, it is no longer possible to assess their quality or performance by mere inspection. Decisions are now generally based on test data, and laboratory accreditation provides some assurance of the technical proficiency and competence of a laboratory to assess a product's or service's conformance to a set of prescribed standards. The competence of laboratories which perform testing within an evaluation/approval system is vital in securing acceptance of their test results by other countries. Mutual acceptance of laboratory test results between countries can reduce unnecessary retesting and serve as a basis for increased opportunities for international trade.

The international General Agreement on Tariffs and Trade (GATT) has as one of its major components the Agreement on Technical Barriers to Trade (usually referred to as the Standards Code). The framers of the standards Code, including the United States, recognized that activities, such as laboratory accreditation and the mutual acceptance of test results by signatories, can either expedite or seriously hinder the free flow of goods in international commerce. However, the Code does not obligate signatories to recognize test results or certification marks from another country. The code established a mechanism to enable signatories to the code to enter into bilateral negotiations to discuss the reciprocal acceptance of test results. One method for ensuring test data acceptance is the mutual recognition of the scheme or schemes which exist in each country for the accreditation of testing laboratories. Assurance that there is an adequate laboratory accreditation scheme can provide another country with some degree of confidence in test results of laboratories accredited under that scheme. As multilateral trade negotiations continue, one goal is to broaden the scope of the Code in this important area.

The importance of mutual recognition of test data and laboratory accreditation schemes has also been acknowledged in other international arenas. The Organization for Economic Cooperation and Development (OECD) has worked extensively on developing its Code of Good Laboratory Practice to facilitate the international exchange of data on most chemical products. Events such as the formation of a European single Market, the signing of the Free Trade Agreement between the United States and Canada, and the undertaking of free trade negotiations with Mexico have further emphasized the need to address laboratory accreditation issues. Mutual recognition of test data is vital in the prevention of trade barriers that result from unnecessary repetitive testing.

\section{SOME FACTORS FOR CONSIDERATION}

Not all laboratory accreditation programs are equally thorough, nor are all laboratory accrediting bodies equally competent. The users of accreditation, accredited laboratories, and the test data produced by accredited laboratories should be aware of the following factors when evaluating a laboratory's accreditation or an accreditation process. These factors may affect the ability of the accreditation process to provide assurance that an accredited laboratory is capable of producing accurate and precise test data. 


\section{Standards/Test Methods Used}

The choice of standards and test methods used in a laboratory accreditation scheme has a significant impact on the validity of the scheme and the accuracy, representativeness, and reproducibility of the results. To test a product or service against a standard, a test procedure or method must be used. A test result can have value only if the method used to generate it is capable of producing accurate and precise results.

It is almost impossible to avoid all possible misinterpretations in the writing of a standard. However, many standards developers fail to test and adjust standards to accommodate problems encountered during implementation, particularly during testing situations. Conformance to characteristics specified in a standard may not be accurately assessable with any kind of practical test method.

Standards may not cover all essential characteristics of a product necessary to ensure a given level of quality or safety, or they may contain unnecessary specifications that are not based on well-documented research or information. Specifications may be inadequate or set too low to ensure an acceptable level of product quality or safety. If such problems with test methods and standards are significant, the test result can be misleading or useless.

\section{Open Access to the System}

In general, participation in the accreditation process should not be conditional upon a laboratory's membership in any association or organization. It is usually not desirable for the accrediting body to have any relationship with the test laboratory that might influence the accreditation process. Laboratories holding membership in the accrediting organization might develop sufficient influence over the accrediting body to affect the accreditation decision. Furthermore, unjustified fees, financial requirements, or other conditions for application, which restrict participation and are not relevant to the competency of the laboratory should be avoided.

\section{Conflicts-of-Interest}

If the accreditation process is to be credible, the accrediting body and its assessors should be free from any outside influence which might bias the results of the accreditation process. The body should have sufficient financial resources to allow it to refuse accreditation should that prove necessary. No relationship should exist between the laboratory and the accreditation body or its assessors which could in any way influence the objectivity and outcome of the accreditation process.

\section{Effective Quality System}

The presence of an effective quality system in the accreditation scheme is important in maintaining confidence in the accreditation process. ISO/IEC Guide 54 notes that the system should be "appropriate to the type, range and volume of work performed." The system should be documented and should include "quality assurance procedures specific to each step of the accreditation process." Procedures for ensuring adequate feedback, taking corrective actions, and handling appeals should also be included. Such documentation should be available to the accreditation staff, and responsibility for the system should be assigned to a person having access to the highest management levels. The quality 
system should be periodically reviewed and revised as needed to ensure the continued effectiveness of the system.

\section{Staff Training, Experience, and Records}

Assessors should have the knowledge and experience necessary to perform all required assessments in the accreditation process, including detailed knowledge of the assessment criteria and the standards, test methods and equipment

involved. Financial benefit accruing to the accreditation body from the training of assessors should be avoided to discourage the training of marginally qualified assessors. The accrediting body should also have a means of ensuring fair and equitable selection and assignment of assessors. Assessor reports and recommendations should be submitted without editing to the accrediting body. A proposed standard for selecting qualified assessors is currently under consideration by ISO.

\section{Adequate Records}

The accrediting body should maintain adequate records on the data collected, findings and reports related to all assessments performed; the qualifications, training and experience of each assessor; the assessment procedures used; and the laboratories accredited. All documentation regarding a laboratory should be restricted to persons or organizations considered by the accreditation body as having a legal right to such records.

\section{Adequate Follow-up and Enforcement}

The accrediting body should have mechanisms in place to minimize the potential for fraud or deception on the part of a laboratory regarding its accreditation status or the meaning of that status. This includes arrangements for periodic reassessments of each accredited laboratory to ensure its continued compliance with the accreditation criteria. The accrediting body should also have procedures which permit the swift withdrawal of accredited status from laboratories which fail to comply with the terms and requirements for accreditation, as well as procedures for notifying other interested parties of a change in accreditation status.

\section{Lack of Recognition of Laboratory Accreditation Schemes}

Lack of recognition or acceptance of a laboratory accreditation scheme by other parties can necessitate extensive retesting of a product or service at considerable expense in terms of both time and money. In some cases, lack of recognition results from inadequate knowledge or information about the program and/or the vested interests of others, rather than problems in the program itself. Lack of recognition can result in the need for a laboratory to obtain multiple accreditations for the same or essentially the same testing services, sometimes based on all or most of the same accreditation criteria. For example, based on information collected by Mr. Charles Hyer, laboratories desiring to be accredited/designated nationwide to conduct electrical safety-related testing of construction materials have to gain the acceptance of at least 43 states, more than 100 local jurisdictions, the International conference of Building officials (ICBO), the Building Officials and Code Administrators (BOCA), the Southern Building Code Congress International (SBCCI), a number of federal agencies, as well as by several large corporations. 
Some federal agency laboratory accreditation programs have gained recognition by other agencies. These include the NVLAP program -- currently required by the Department of Housing \& Urban Development (HUD), the Federal Communications Commission (FCC), the Federal Trade Commission, the Environmental Protection Agency (EPA) the Nuclear Regulatory Commission (NRC) and parts of the Department of Defense (DOD). Additional agencies are likely to require NVLAP accreditation as new laboratory accreditation programs (LAPs) are established. Reports on laboratories (that also test pesticides and environmental contaminants) from the Food and Drug Administration's (FDA) toxicology laboratory monitoring program are shared with the Environmental Protection Agency (EPA). In some cases, private sector laboratory accreditation programs are recognized and accepted by federal, state and local government authorities for regulatory, procurement or other purposes. Programs that are well accepted are usually more cost effective since the need for multiple and duplicative assessments is reduced.

\section{Mutual Recognition Agreements (MRAs)}

Lack of recognition can be overcome through mutual recognition agreements (MRAs) under which two or more parties agree to recognize the competence of laboratories accredited by the other(8). Many problems may arise with mutual recognition agreements, however, including lack of clarity or the inclusion of poorly defined terms and responsibilities in the written agreement. One of the least understood problems involves the identity and authority of the signatories to the agreement. For example, two accrediting bodies can agree to recognize each other's laboratory accreditation system. If the acceptance body for the test data produced by the accredited laboratories (usually the agency with regulatory respsonsibility for the product or service) is not party to the agreement, it may not be willing to accept data generated from laboratories accredited under the other accrediting body's system. The value of any agreement is then questionable. This can be overcome if each accrediting body is willing to extend its own accreditation to a laboratory that has been accredited by the other party. However, under this arrangement, each party may assume responsibility for, and the liability and risks associated with, the other party's work. As a result, the establishment of effective MRAs is usually a very complex undertaking.

\section{Multiple Accreditations}

Laboratories involved in multiple types of testing may need to obtain accreditation from more than one U.S. agency or organization. The 1989 GAO report noted that it was unlikely that a laboratory would be designated/ accredited to perform the same type of testing by more than one federal government agency, but that it was quite possible that a laboratory would be accredited by more than one agency for different types of testing. For example, it may need accreditation by one agency to test human tissue for disease; by another to test water for chemicals and bacteria; and by yet another to test meat and poultry for moisture, fat, protein, and salt. However, as noted above, it is not uncommon for a laboratory to need multiple state and local government accreditations/designations to conduct the same type of testing.

Laboratory accreditation programs are frequently narrow in their scope -designating or accrediting laboratories to test only a narrowly defined range of products or services within the agency's or organization's area of responsibility. The results of laboratory assessments from these programs are usually of only limited use to other federal agencies and organizations. A laboratory which offers a broad range of testing services may need multiple 
accreditations increasing the laboratory's cost of doing business and possibly restricting entrance into additional testing areas.

\section{An Adequate Appeals System}

Disagreements among parties involved in a accreditation program may occasionally arise. Provision should be made within the program for an impartial appeals mechanism to handle disagreements that cannot otherwise be resolved. Procedural requirements should be in writing with minimal limitations on the timing of appeals, and on who may file.

\section{Lack of Failures}

If all applicants are accredited, the effectiveness of the accreditation program should be reviewed. It is possible that the accreditation program has been effective and unqualified testing laboratories have not applied. However, it is, also possible that the accreditation program has not been effective in uncovering weaknesses in laboratory operations and the program's methods and criteria need to be overhauled. Causes for the lack of failures should be investigated to determine if the program is still effective.

\section{Accreditation Costs}

The costs involved in accreditation can be cause for serious concern for all laboratories, particularly for smaller laboratories or those that offer a broad range of testing services. Such costs must be balanced against the amount of new testing work likely to result.

Multiple accreditations may be required to perform testing for different countries, or even for more than one state and/or local jurisdiction. Multiple accreditations may also be required for different products or testing fields -all of which can considerably increase total accreditation costs. These costs must ultimately be passed on to the users of the testing services.

\section{SUMMARY}

Laboratory accreditation does not guarantee the quality of a laboratory's test results. Laboratory accreditation only means that the laboratory is capable of performing specified test methods and procedures correctly, not that it has competently tests all products in each and every instance. Moreover, accreditation provides assurance only about a laboratory's capability within the scope or areas for which accreditation was granted. If a laboratory is accredited to test concrete, no assurance is provided regarding that laboratory's ability to test any product other than concrete. It should also be noted that lack of accreditation does not necessarily imply lack of technical competence, since not all laboratories seek or are required to be accredited, or there may be no accreditation programs in the laboratory's field of operation.

Users of test results must understand the laboratory accreditation process, the criteria used, and the scope of accreditation in order to assess the value of that accreditation and to make intelligent choices regarding the use of the test results produced by laboratories accredited under that process. While laboratory accreditation, standardization, quality system registration, and certification are distinct activities, the four together can serve as a basis for increased or diminished opportunities for national and international trade. Mutual acceptance 
of laboratory test results among entities in the United States and between the United States and other countries reduces the need for repetitive and costly retesting and is an important step towards facilitating national and international commerce. 


\section{REFERENCES}

1/ Alan Bryden, "Laboratory Accreditation Worldwide," ILAC Technical Seminar, October $20,1988$.

2/ American Society for Testing and Materials (ASTM) Standard E 1224-88: Standard Guide for Categorizing Fields of Testing for Laboratory Accreditation; Standard $E$ 548-84: Practice for Preparation of Criteria for Use in the Evaluation of Testing Laboratories and Inspection Agencies; Standard E 994-84: Standard Guide for Laboratory Accreditation Systems; Philadelphia, PA.

3/ Thomas A. Ratliff, Jr., The Laboratory Quality Assurance System: A Manual of Quality Procedures with Related Forms. Van Nostrand Reinhold, New York, NY, 1989.

4/ International Organization for Standardization (ISO) and the International Electrotechnical Commission (IEC), Guide 2 - Definitions (1986), Guide 25 General Requirements for Competence of Calibration and Testing Laboratories (1990), Guide 38 - Requirements for the Acceptance of Testing Laboratories (1983), Guide 43 - Proficiency Testing (1984), Guide 45 - Presentation of Test Results (1985), Guide 54 - Recommendations for the Acceptance of Accreditation Bodies (1988), Guide 55 - Recommendation for the Operation of Testing Laboratory Accreditation Systems (1988), ISO/IEC, Geneva, Switzerland.

5/ U.S. General Accounting office, Laboratory Accreditation: Requirements Vary Throughout the Federal Government, March 1989.

6/ International Trade Administration (ITA), The Tokyo Round Agreements: Technical Barriers to Trade - Volume 4, Dept. of Commerce, Washington, D.C., September 1981.

I/ Brian C. Belanger, "Traceability: An Evolving Concept," ASTM Standardization News, October 1980, pp. 22-28. 


\section{APPENDIX \\ INFORMATION AND PUBLICATIONS \\ AVAIIABRE FROM \\ Standards Code and Information Program \\ National Institute of Standards and Technology \\ Administration Building, Room A629 \\ Gaithersburg, MD 20899}

(301) $975-4029$

- The ABC's of Standards-Related Activities in the United States (NBSIR 87-3576)

This report provides an introduction to voluntary standardization, product certification and laboratory accreditation for a reader who is not fully familiar with these topics. It highlights some of the more important aspects of these fields; furnishes the reader with both historical and current information on these topics; describes the importance and impact of the development and use of standards; and serves as background for using available documents and services. Order as PB 87-224309 from NTIS.

- The ABC'S of Certification Activities in the United States (NBSIR 88-3821)

This report, a sequel to NBSIR 87-3576, The ABC'S of Standards-Related Activities in the United States, provides a further introduction to certification for a reader who is not entirely familiar with this topic. It highlights some of the more important aspects of this field, furnishes the reader with information necessary to make informed purchases, and serves as background for using available documents and services. Order as PB 88-239793 from NTIS.

\section{- Laboratory Accreditation in the United States (NISTIR 4576)}

This report, a sequel to NBSIR 87-3576, The ABC'S of Standards-Related Activities in the United States and NBSIR 88-3821, The ABC'S of Certification Activities in the United States, provides the reader with additional information on one standards-related activity --laboratory accreditation. This document serves as an introduction to laboratory accreditation for those not fully familiar with this subject. The report highlights some of the more important aspects of laboratory testing and accreditation, furnishes the reader with information necessary to make informed decisions, and serves as background for using available documents and services.

\section{- Directory of International and Regional organizations Conducting}

Standards-Related Activities (NIST SP 767)

This directory contains information on 338 international and regional organizations which conduct standardization, certification, laboratory accreditation, or other standards-related activities. It describes their work in these areas, as well as the scope of each organization, national affiliations of members, U.S. participants, restrictions on membership, and the availability of any standards in English. Order as SN 003-003-02937-8 from GPO.

- Directory of Federal Government Laboratory Accreditation/Designation Programs (NIST SP 808)

This directory contains information on federal government laboratory accreditation and similar type programs conducted by the federal government. These programs designate a set of laboratories or other entities to conduct testing to assist federal agencies in carrying out their responsibilities. Order as SN 003-003-03069-4 from GPO. 
- Standards Activities of Organizations in the United States (NIST SP 806)

The directory summarizes the standardization activities of more than 750 organizations in the United States, including federal agencies and approximately 425 private sector groups that are involved in standards development. It also contains sources of standards documents and information, a subject index, and related listings that cover acronyms and initials, defunct bodies and organizations with name changes. Order as SN 003-003-03070-8 GPO.

\section{- Directory of Private Sector Product Certification Programs (NIST SP 774 )}

This directory presents information from 132 private sector organizations in the United States which engage in product certification activities. Entries describe the type and purpose of each organization, the nature of the activity, product certified, standards used, certification requirements, availability and cost of services, and other relevant details. Order as SN 003-003-02984-0 from GPO.

- Directory of Federal Government Certification Programs (NBS SP 739)

This directory presents information on U.S. Government certification programs for products and services. Entries describe the scope and nature of each certification program, testing and inspection practices, standards used, methods of identification and enforcement, reciprocal recognition or acceptance of certification, and other relevant details. Order as SN 003-003-02852-5 from GPO.

- Barriers Encountered by U.S. Exporters of Telecommunications Equipment (NBSIR 87-3641)

This report addresses the perceived institution of unreasonable technical trade barriers by major European trading partners to the export of telecom products and systems by U.S. companies. The GATT technical office, which has responsibilities to assist U.S. exporters to take advantage of trade opportunities, informally contacted over a period of six months, telecom companies and agencies to assess the extent of unreasonableness in foreign national standards, regulations, testing and certification requirements, and accreditation procedures. Order as $\mathrm{PB}$ 88-153630 from NTIS.

- A Review of U.S. Participation in International standards Activities (NBSIR 883698)

This report describes the role of international standards, their increasingly significant importance in world trade, and the extent of past and current U.S. participation in the two major international standardization bodies - ISO and IEC. The degree of U.S. participation covers the 20 year period 1966-1986. A coarse analysis of data indicates some correlation between U.S. participation and recent export performance for several major product categories. Order as PB 88164165 from NTIS.

- An Update of U.S. Participation in International Standards Activities (NISTIR 89-4124)

This report presents updated information on the current level of U.S. participation in ISO and IEC (reference: NBSIR 88-3698). Order as PB 89-228282/AS from NTIS.

- A Summary of the New European Community Approach to Standards Development (NBSIR 88-3793-1)

This paper summarizes European Community (EC) plans to aggressively pursue its goal of achieving an "internal market" by 1992 and the standards-related implications of such a program on U.S. exporters. Order as PB 88-229489/AS from NTIS. 
- Trade Implications of Processes and Production Methods (PPMs) (NISTIR 904265)

This report discusses processes and production methods (or PPM's) and their relationship to trade, the GATT Agreement on Technical Barriers to Trade, and traditional product standards used in international commerce. The report provides background information on PPM's, a suggested definition, and the possible extension of their application from the agricultural sector to industrial products. Order as PB 90-205485 from NTIS.

- Directory of European Regional Standards-Related Orqanizations (NIST SP 795)

This publication contains information on European regional organizations which are involved in standardization, certification, laboratory accreditation, or other related activities. The directory describes their work in these areas, as well as other information of interest. Order as SN 003-003-03038-4 from GPO.

\section{[SEE LAST PAGE FOR NTIS AND GPO CONTACTS]}

The following documents are available upon request from the oSCI office.

0 tbt news

This newsletter provides information on government programs and available services established in support of the GATT Agreement on Technical Barriers to Trade (Standards Code). tbt news reports on the latest notifications of proposed foreign regulations; bilateral consultations with major U.S. trade partners; programs of interest to U.S. exporters; and availability of standards and certification information. Subscription is free upon request.

\section{- Technical Barriers to Trade}

This booklet explains the basic rules of the international Agreement on Technical Barriers to Trade negotiated during the Tokyo Round of the Multilateral Trade Negotiations (MTN), and describes Title IV of the U.S. Trade Agreements Act of 1979 which implements the United States' obligations under the Agreement. The Agreement, popularly known as the standards Code, was designed to eliminate the use of standards and certification systems as barriers to trade. The booklet describes the functions of the Departments of Commerce and Agriculture, the office of the U.S. Trade Representative, and the State Department in carrying out the U.S.'s responsibilities.

\section{- GATT Standards Code Activities}

This brochure gives a brief description of NIST's activities in support of the Standards Code. These activities include operating the U.S. GATT inquiry point for information on standards and certification systems; notifying the GATT secretariat of proposed U.S. regulations; assisting U.S. industry with trade-related standards problems; responding to inquiries on foreign and U.S. proposed regulations; and preparing reports on the standard code.

\section{- GATT Standards Code Activities of the National Institute of standards and} Technology

This annual report describes the GATT Standards code activities conducted by the office of Standards code and Information for each calendar year. NIST responsibilities include operating the GATT inquiry point, notifying the GATT Secretariat of proposed U.S. Federal government regulations which may affect trade, assisting U.S. industry with standards-related trade problems, and responding to inquiries about proposed foreign and U.S. regulations. 
- Report to the United States Congress on the Agreement on Technical Barriers to Trade - "Standards Code"

This triennial report describes the programs and activities established to implement the Standards Code in the United States by the four responsible U.S. government agencies: Office of the U.S. Trade Representative; Department of Commerce (National Institute of Standards and Technology, International Trade Administration); Department of Agriculture and Department of state.

- Free handout material on office activities and standards-related information such as: government sources of specifications and standards; foreign standards bodies; U.S. standards organizations; and a brochure on the National Center for standards and Certification Information (NCSCI).

In addition to general inquiry services, the following assistance is also available:

\section{- EC Hotline}

This hotline reports on draft standards of the European Committee on Standardization (CEN), the European Committee for Electrotechnical Standardization (CENELEC), and the European Telecommunications Standards Institute (ETSI). It also provides information on selected EC directives. The recorded message is updated weekly and gives the document number, product, and closing date for comments. The hotline number is (301) 921-4164 (not toll-free).

\section{- GATT Hotline}

A telephone hotline provides current information received from the GATT Secretariat in Geneva, Switzerland, on proposed foreign regulations which may significantly affect trade. The recorded message is updated weekly and gives the product, country, closing date for comments (if any) and Technical Barriers to Trade (TBT) notification number. The hot line number is (301) 975-4041 (not toll-free).

- NCSCI provides assistance to U.S. and foreign exporters in obtaining current standards, regulations and certification information for the manufacture of products. To aid foreign exporters, NCSCI also provides directory information of state offices prepared to respond to queries concerning conditions to be met by goods for sale in their state.

\section{Publication Ordering Information}

NTIS - National Technical Information Service 5285 Port Royal Road

Springfield, VA 22161

(703) $487-4650$

GPO - Superintendent of Documents U.S. Government Printing office Washington, DC 20402 (202) 783-3238 



\begin{tabular}{|c|c|c|}
\hline \multirow[t]{3}{*}{$\begin{array}{l}\text { NIST-114A } \\
\text { (REV. 3-89) }\end{array}$} & \multirow{3}{*}{$\begin{array}{l}\text { U.S. DEPARTMENT OF COMMERCE } \\
\text { NATIONAL INSTITUTE OF STANDARDS AND TECHNOLOGY } \\
\text { BIBLIOGRAPHIC DATA SHEET }\end{array}$} & $\begin{aligned} \text { 1. PUBLCATION OR REPORT NUMBER } \\
\text { NISTIR } 4576 \\
\end{aligned}$ \\
\hline & & PERFORMING ORGANIZATION REPORT NUMBEF \\
\hline & & $\begin{array}{l}\text { 3. PUBUCATION DATE } \\
\text { May } 1991\end{array}$ \\
\hline
\end{tabular}

4. TITLE AND SUBTITLE

$$
\text { LABORATORY ACCREDITATION IN THE UNITED STATF.S }
$$

5. AUTHOR(S)

Maureen A. Breitenberg

6. PERFORMING ORGANIZATION (IF JOINT OR OTHER THAN NIST, SEE INSTRUCTIONS)

U.S. DEPARTMENT OF COMMERCE

NATIONAL INSTITUTE OF STANDARDS AND TECHMOLOGY

GAITHERSBURG, MD 20899

7. CONTRACT/GRANT NUMBER

8. TYPE OF REPORT AND PERIOD COVERED Final

9. SPONSORING ORGANIZATION NAME AND COMPLETE ADDRESS (STREET, CITY, STATE, ZIP)

Same as Above.

10. SUPPLEMENTARY NOTES

DOCUMENT DESCRIBES A COMPUTER PROGRAM; SF-185, FIPS SOFTWARE SUMMARY, IS ATTACHED.

11. ABSTRACT (A 200-WORD OR LESS FACTUAL SUMMARY OF MOST SIGNIFICANT INFORM.ATION. IF DOCUMENT INCLUDES A SIGNIFICANT BIBUOGRAPHY OR LTERATURE SURVEY, MENTION IT HERE.)

This paper, the third in a series that includes NBSIR 87-3576, The ABC's of

Standards-Related Activities in the United States, and NBSIR 88-3821, The ABC'S

of Certification Activities in the United States, is designed to provide

information on laboratory accreditation to readers not entirely familiar with

this topic. This report highlights some important aspects on the topic,

furnishes information necessary to make informed decisions on the selection and use of laboratories, and serves as background for using other available documents and services. Readers interested in this area may also wish to review NIST SP 808, Directory of Federal Govermment Laboratory Accreditation/Designation proorams, which provides updated information on federal govermment laboratory accreditation and similar type programs conducted by the federal government. companion volumes on state and local government and private sector laboratory accreditation programs are currently in preparation.

12. KEY WORDS (6 TO 12 ENTRIES; ALPHABETICAL ORDER; CAPITAUZE ONLY PROPER NAMES; AND SEPARATE KEY WORDS BY SEMICOLONS) accreditation; calibration; conformance testing; laboratory accreditation; NVIAP; quality assurance; testing

13. AVALLABIUTY

$\mathrm{XX}$ UNUMITED

FOR OFFICIAL DISTRIBUTION. DO NOT RELEASE TO NATIONAL TECHNICAL INFORMATION SERVICE (NTIS).

ORDER FROM SUPERINTENDENT OF DOCUMENTS, U.S. GOVERNMENT PRINTING OFFICE, WASHINGTON, DC 20402.

ORDER FROM NATIONAL TECHNICAL INFORMATION SERVICE (NTIS), SPRINGFIELD, VA 22161.

14. NUMBER OF PRINTED PAGES

30

15. PRICE

A03 


